\title{
The FFPS Bat Project
}

\author{
Tony Hutson
}

For more than four years the FFPS's Bat Project has received much publicity and acclaim, but more importantly it has resulted in a heightened awareness of the special problems that bats face. Here, the Bat Conservation Officer describes the history of the project and its activities.

Bats, a diverse group with over 950 species, form a quarter of the world's mammals and in many tropical forests and temperate countries form a much higher proportion of the local mammal fauna. In common with almost any other large group of animals, some species occasionally come into conflict with man. That conflict is often exacerbated by their secretive and nocturnal activity, which makes it difficult to accumulate the knowledge needed to deal with the problems and to dispel myths and misunderstandings.

At around the turn of the century several states of the world introduced laws that protected insectivorous bats as valuable controllers of insect pests. It was many years before the full importance of fruit bats as pollinators and seed dispersers could be impressed. But such laws conflicted with attitudes that regarded bats as 'pests'. Research has increased our understanding and interest, and this has led to concerns about the diverse threats, the precarious status of many species and the damage that could be done through ill-considered or unthinking human activities. Particularly through the 1970 s and into the 1980 s these concerns became supported by more positive action.

From 1977 the FFPS supported Dr Stebbings as founder Chairman of the IUCN Chiroptera Specialist Group and, because of the special conservation needs of bats, in 1982 founded Bat Conservation International $(\mathrm{BCl})$ within the Society. Merlin Tuttle (USA) was invited to be joint Chairman. Because the major conservation The FFPS Bat Project problems originated in the USA a generous grant from The Vincent Wildlife Trust (VWT) allowed a full-time officer to be employed in the USA working under Tuttle. The American office developed and after two years became independent of the FFPS. Merlin Tuttle still runs $\mathrm{BCI}$, now based in Austin, Texas.

In the 1970s and early 1980s Bob Stebbings found it increasingly difficult to cope singlehandedly with the demands for help and advice on bats throughout Britain and worldwide. As a result, John A. Burton (then the Society's Executive Secretary) initiated the FFPS Bat Project. In 1982 the bat part of the UK's Wildlife and Countryside Act 1981 (WCA) came into effect, giving protection to all UK bats and their roosts, and requiring consultation over any activity that might affect them. By the time the FFPS and the Mammal Society held a joint meeting to discuss bat conservation in March 1984 there were already 23 local groups dedicated to pursuing bat conservation and in particular to helping the Nature Conservancy Council (NCC) make the WCA effective. Demand for this one-day meeting was so great that it had to be repeated on the following day! The time was right for the FFPS to integrate the UK work with the FFPS's international obligations.

When, in June 1984, the FFPS appointed the first non-governmental Bat Conservation Officer (BCO) (the author) no one could have foreseen the scale of the burgeoning of interest in bats in the UK. One-third of the BCO's time was 
allocated for international work, but the demand in the UK was so great that, to everybody's regret, it has never been possible to achieve that target. The UK role was to encourage public interest and awareness and deal with general enquiries, to act as a support and liaison centre for the UK volunteer bat groups, to prepare and supply materials and information and to respond to particular conservation issues, be they threats to important roosts or more general issues, such as the encouragement of the wider use of chemicals less toxic to mammals in remedial timber treatment.

Public interest needed little encouragement and each year the project has had to deal with between 3000 and 4000 general and specialist requests for information. Some of these have come in floods. An article in RSPB's Birds magazine in 1985 and the BBC's film Bats Need Friends in 1987 each resulted in over 1000 letters. This burden of enquiries would have put severe restraints on the project without some development.

In December 1984, the FFPS appointed an Assistant Bat Conservation Officer (Simon Mickleburgh) under a one-year grant from the Greater London Council. Additional funding was obtained for a second year, but with the FFPS's impending move out of London, no such funding was sought for $1987 / 88$. The initial funding was principally to survey the bats of the London area, to establish a London Bat Group and to provide information for the public and those professions whose activities impinge on bats; thus much of this work, though directed and developed for London, was equally applicable to other areas. The results of the survey were published (Mickleburgh, 1987). As the London objectives were achieved, so this post became more one of scientific and technical assistance with increased involvement in international conservation.

As a major push towards public awareness 1986 was declared National Bat Year and a second Assistant Bat Conservation Officer (Joan Tait) was appointed to help with publicity and education. This post too has been maintained, with the greater emphasis now on 'education' and batgroup servicing (and with Joan Tait recently replaced by George Bemment).

28
In its aim to raise public awareness of bat conservation problems National Bat Year was very successful. With the local groups doing their bit in their own areas, co-ordination by FFPS and with Bob Stebbings ever prominent, a great deal of publicity was engendered if the 19,000 columninches in newspapers and magazines is a measure. Radio and television also gave bats extensive coverage, ranging from a house-bat 'problem' in The Archers, the UK's long running radio serial, to the 50-minute television film Bats Need Friends (in which, if the bats were not the stars, Bob Stebbings certainly was). The FFPS also arranged a six-week exhibition at the British Museum (Natural History) and Bats for an Afternoon at London's Queen Elizabeth Hall, a programme of talks, films and demonstrations interspersed with readings of poetry and the writings of naturalists. The exhibition that accompanied it was probably the largest collection of bat-related material ever displayed.

In order to raise public awareness, we have given talks, led evening walks, given radio and television interviews and have written many articles for journals and magazines. While it may be difficult to quantify a change in public attitude to bats, the change in the media approach has been marked: far fewer reporters feel the need to preface an item on bats with a discussion on Dracula, and more interview and report with interest and curiosity rather than the incredulity of early days. We also correct published misinformation, respond to particular threats, advise on publications, provide information, materials or contacts about UK bats and batwork for media use at home and abroad, and advise on the protection, preservation, improvement and creation of roosts, particularly in buildings and in underground sites used for hibernation. At present we are devoting most of our energy to getting bat conservation more widely considered by those whose activities affect bats in buildingsbuilding societies, local authorities, surveyors, architects, chemical suppliers, builders' merchants, builders, plumbers and timber treatment operatives.

The widespread use of highly toxic chemicals in remedial timber treatment and pest control is a major area of concern. Such chemicals are being regarded with increased suspicion throughout 


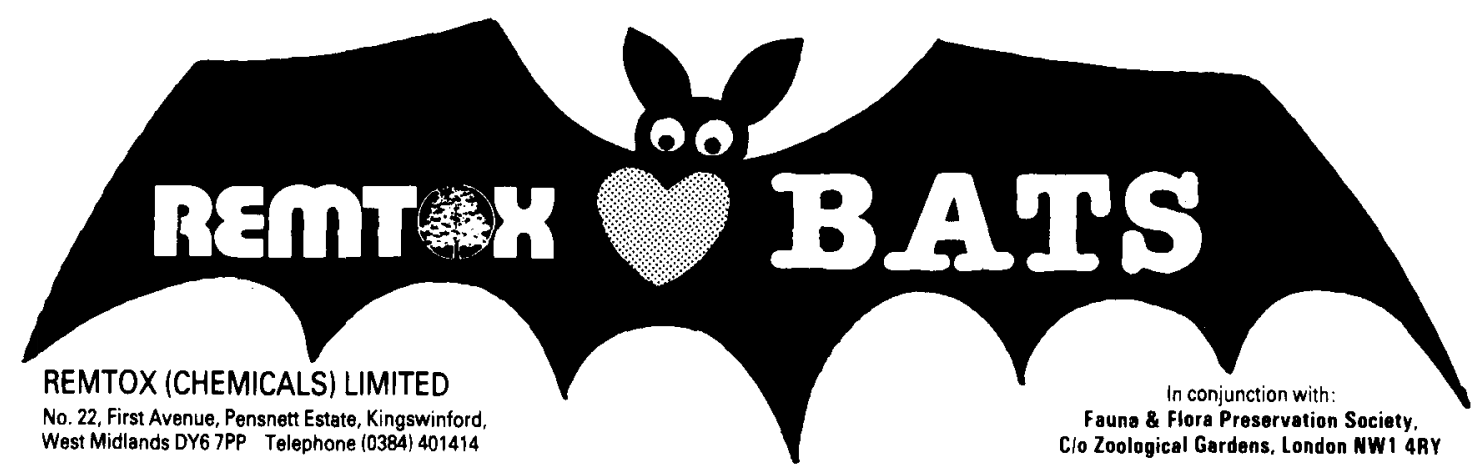

Remtox (Chemicals) Ltd has used the design of the FFPS bat sticker as part of its drive to encourage the wider use of safer chemicals.

the trade and the efforts of bat conservationists are encouraging the switch to less toxic chemicals. Some chemical companies, for example, Remtox, have already switched completely and have actively helped the FFPS Bat Project. The FFPS also acted to get one misrepresented chemical withdrawn from the market. Now, through the provision of information and training, we hope to reduce the number of roosts lost through accidental or unthinking renovation and other building work. So far the response has been very encouraging, at times almost overwhelming. The general information sheets and posters, modified and improved over the years, the slide-packs and exhibitions, all still serve a purpose, but have been supplemented with more specialist material designed for particular target groups.

All this would have limited effect without the efforts of the local bat groups (now numbering 70 or so). In 1984 Bat Groups of Britain (BGB) was set up, an umbrella organization consisting of individuals and representatives of those organizations involved in UK bat conservation (FFPS, NCC, Royal Society for Nature Conservation), funding (World Wide Fund for Nature, NCC, VWT), research (Institute of Terrestrial Ecology, Mammal Society, universities) and the local bat groups themselves. It holds quarterly meetings and about 300 people attend its annual conference.

The organization of the local bat groups varies enormously, since they are self-generated and voluntary. Some are independent, some are The FFPS Bat Project affiliated at various levels to the county nature conservation or wildlife trusts. The level of fundraising, education, research or direct conservation activity all vary greatly, as does their internal organization. Guidance, but not rules, is offered to these groups and there is no obligation to support a central office (would that there were!), only encouragement of individual members to subscribe to appropriate organizations (such as the FFPS, Mammal Society or local trusts). Their membership is largely amateur, but encompasses a very broad range of useful talents. In common they exist to educate about bats, to give advice on bat conservation and to record species distribution, status and behaviour in their areas.

The FFPS is the BGB's secretariat, accumulating and distributing information, giving advice and support to bat groups, and acting as a national body on their behalf. The FFPS also administers the BGB Support Fund, set up to provide small grants towards conservation projects. Its funds come from the sale of bat goods, donations and from the VWT.

These two areas, relating to the public and bat group liaison, have formed the basis of the project. The first 18 months was a period of development and the next year was devoted to National Bat Year (with funding from NCC, VWT and WWF(Heinz)). In 1987 a Partnership was formed with NCC and VWT and in this period of consolidation we tried to maintain a relatively low profile in order to prepare materials for which there was an overdue need. That Partnership has 


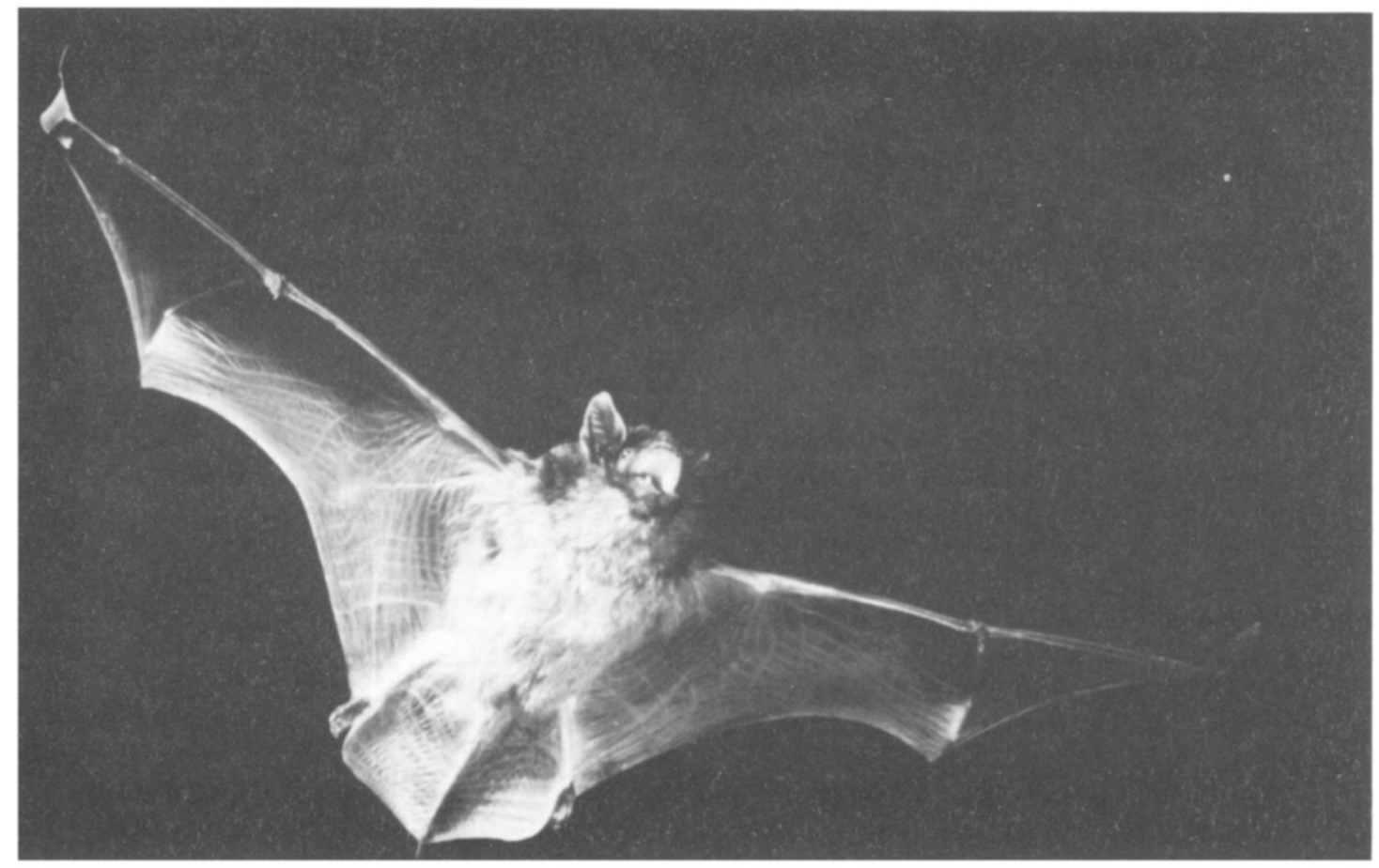

The serotine bat Eptesicus serotinus, one of the largest and most house-oriented bats in the UK, is the subject of a PhD study funded through the Bat Project (F. R. Greenaway).

continued in 1988 with a more overt element in its approaches to the building trade and allied industries.

The project has retained some time to do things that FFPS considers important, but outside the scope of the Partnership's agreed areas of priority. Thus the project is supervising a $\mathrm{PhD}$ funded by a member donor. Colin Catto, registered at Aberdeen University (with Professor Paul Racey), is doing his field research in Sussex into the feeding ecology and breeding behaviour of the serotine bat, one of the UK's most houseoriented bats and one for which we need more information to give good management advice. This study has greater relevance since the discovery of a rabies-related virus in serotines in continental Europe. Although not known to be a human problem it is being watched with caution and is being looked for here. The UK's Ministry of Agriculture Fisheries and Food is examining bats and the $\mathrm{BCO}$ visits their laboratories to identify specimens submitted for testing. The project also acts as a source of information, advice and 30 materials for a range of other conservation bodies. We monitor the effects of legislation, promote research and attend international meetings.

International work on bats also falls outside the remit of the Partnership funding. One of the most significant involvements in this area of activity was initiated by John A. Burton. He was one of a small group that prepared an outline proposal put to the 1985 meeting of the Bonn Convention on the Conservation of Migratory Species of Wild Animals to introduce a European Bat Agreement. JAB and the $\mathrm{BCO}$ were involved in a UK working group (with WWF, Department of the Environment, NCC and Foreign and Commonwealth Office) to discuss a draft Agreement drawn up by WWF. This culminated in an international meeting in November 1987 in London when government and bat representatives from 11 European countries agreed a final text for a formal Agreement on the Conservation of Bats in Europe. This has recently been circulated to European governments with a view to a signing 


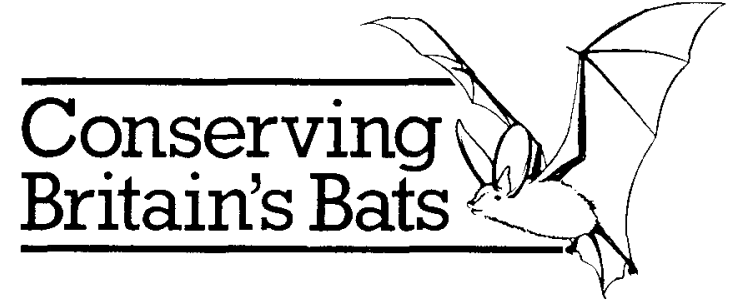

The logo designed for the Partnership between the FFPS, the Nature Conservancy Council and The Vincent Wildlife Trust.

\section{Publications produced by the Bat Project}

Newsletter

Bat News. Editor: A. M. Hutson. 8pp. quarterly newsletter, illustrated. 1984-present. About 75\% UK, 25\% international. For Bat Groups of Britain and IUCN Chiroptera Specialist Group. News, views, articles, announcements, bat contacts, reviews, appeals etc.

\section{Slide-Pack}

Focus on Bats. 1984. 40 slides with commentary on basic bat biology and conservation. Available on filmstrip or mounted slides with commentary in booklet form or on cassette. Also available on video-tape.

\section{Exhibitions}

Bats. 1985. Five panels with colour photographs, artwork and text discussing bat biology, bat myths/ misunderstandings, Britain's commonest and rarest bats, bat conservation in Britain, plus a sixth panel for individual use (e.g. local bat group).

World Bats. 1986. Six panels with colour photographs and text to discuss bat diversity, behaviour, food, benefits to man, conflicts with man, and conservation.

\section{Poster}

Save our Bats. 1987. A2 colour. Basic information on bat biology, protection and contacts.

\section{Booklets}

Bat Boxes. R. E. Stebbings and S. Walsh. 24 pp. 1985 (2nd edition 1988). History, function, construction and use in conservation of bats.

Bats in Houses. A. M. Hutson. 32 pp. 1987. Details of access and roost potential of houses for those with, or wishing to encourage, bats in buildings.

\section{Leaflets}

Conserving Britain's Bats. 4 pp. 1987. General leaflet for general distribution.

Species Leaflets. Series of 10. 1987-1988. 2 pp. Brief leaflets on individual species or groups of species, primarily for owners of or authorities concerned with roosts of particular species.

Bats Underground - A Conservation Code. $6 \mathrm{pp}$. 1988. Basic biology for cavers, mining historians, etc., code of conduct, grading scheme for sites used by bats, protection/preservation, contacts. ceremony in 1989. The FFPS organized the facilities for this meeting, hosted a reception and presented an introductory background lecture. Consequent upon the European Agreement is the development of a European Bat Action Plan by Bob Stebbings, entitled Conservation of European Bats, with Bat Project involvement in commissioning, discussion of contents and editing.

Another international involvement has been through IUCN's Species Survival Commission. The BCO is secretary to the Chiroptera Specialist Group (with Professor Paul Racey as chairman and about 90 members). The range of activities involved in the work of this group overlaps with the Bat Project's interests, but at times they can be separated to conservation advantage. A major initiative has been a Fruit Bat Action Plan to identify the distribution, status, problems and conservation action required for a group of bats that are important pollinators and seed dispersers, but which suffer many threats. Initially we have been looking at Pteropus spp., the flying foxes, and the FFPS has prepared documentation on the species of the western Indian Ocean as a basis for the project.

The Bat Project has contributed to international meetings in Aberdeen, Czechoslovakia, the Netherlands, France, Costa Rica and London as well as giving a guest lecture on a visit to Poland. It has also acted to try to conserve important hibernation sites in Poland and the Netherlands, and to stop extremely damaging fumigation of caves in Israel. It has drawn attention to the overexploitation of fruit bats, has been involved in attempts to establish a feral colony of an endangered fruit bat, made representations over a number of other particular issues and helped produce the revised bat list for the 1988 IUCN Red List of Threatened Animals.

Even on the international side, enquiries figure highly in the demands on the project, some very general, some very specific. Support is often given to activities abroad. Other areas of activity include the media abroad (including writing articles), advice on expeditions, advice to grants committees, review of or help in writing papers and articles for both scientific journals and magazines. About 25 per cent of the project's newsletter, Bat News, serves as the newsletter of IUCN's Chiroptera Specialist Group. 
'In response to your letter... ref. to the future of the Nietoperek Bat Nature Reserve at the Miedzyrzecki fortification area of western Poland. .

I have pleasure to inform you, that the conception of localization of radioactive waste landfill at Miedzyrzecki fortification area is already not actual any more. There will be no radioactive waste landfill in that area. I believe this information is of significant importance for bat preservation.

Let me also express my sincere gratitude for your concern about bat preservation in Poland.'

\footnotetext{
Part of a letter from Poland's Ministry of the

Environment confirming the protection of

Nietoperek, one of Europe's best bat hibernation sites.
}

In the latter half of 1988 future funding for the Bat Project looked uncertain and so the Society decided that the project should find a new home in 1989. We must thus express extreme gratitude to the Honourable Vincent Weir of The Vincent Wildlife Trust, and currently FFPS's ViceChairman, who has not only helped fund the project for three years, but has now offered to adopt the UK side of the project as of March 1989. It will eventually come under the wing of the Mammal Society. An urgent UK priority is to assess the current state of bat conservation and requirements through a UK Action Plan, while maintaining a national NGO centre for information, as a pressure group and for bat group support.

That the UK activities of the project will continue is good news. Efforts are being made to find ways of continuing the rest of the project. Some European countries have a long history of active bat conservation, many others are just developing and looking for help and advice. Increasingly there is the need for a co-ordinating centre and the UK would be very appropriate. If the European Agreement for bats, proposed by the British Government, is signed, the UK would be a particularly appropriate location for a European bureau for exchange of information and ideas and to monitor the effect of the Agreement. The maintenance of the other international work is also very important. In addition to the Fruit Bat Action Plan many other long-term conservation issues need to be reviewed and many emergency issues need to be tackled.

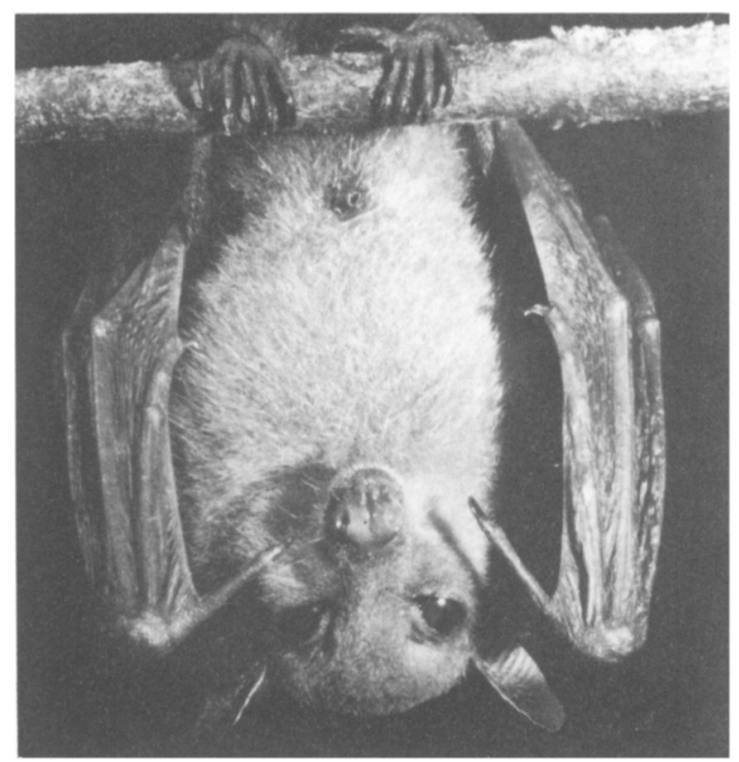

Blossom bat Syconycteris australis from Australia. While most attention has been devoted to the larger fruit bats, especially the flying foxes, these small species are equally important pollinators and many species are at risk (A. M. Hutson).

Throughout the world a greater understanding of bats has brought a greater interest in them and their conservation. The problems of studying them to accumulate data relevant to their conservation are being faced. Their special requirements, their role in the balance of nature and their relationships with man are all being assessed with the aid of modern techniques. For many people fears have become fascination, pests have become prized. The process of giving this diverse group of mammals its rightful place in conservation has begun.

\section{Acknowledgments}

There can be no doubt that none of this would have happened without the enthusiasm, knowledge and personal commitment of John Burton and Bob Stebbings and the support of the FFPS Council. Phil Richardson, joint secretary to $\mathrm{BGB}$, has been a tireless supporter of the project and its aims. In a wide-ranging project such as this, there are many other acknowledgments due, to volunteers who have helped with office work, to donors and funders, and to the enormous number of people who have given help, advice and support. I hope they will know who they are and, on behalf of the project and the Society, I thank them all.

\section{Reference}

Mickleburgh, S. 1987. Distribution and status of bats in the London area. The London Naturalist, 66, 41-91.

Oryx Vol 23 No 1, January 1989 